\title{
Natural and artificial ageing of spruce wood as observed by FTIR-ATR and UVRR spectroscopy
}

\author{
Christelle Ganne-Chédeville ${ }^{1, *}$, Anna-Stiina \\ Jääskeläinen ${ }^{2,3}$, Julien Froidevaux ${ }^{1}$, Mark Hughes ${ }^{2}$ \\ and Parviz Navi ${ }^{1}$ \\ ${ }^{1}$ Bern University of Applied Sciences, Architecture, Wood, \\ and Civil Engineering, Solothurnstrasse 102, 2500 Biel, \\ Switzerland \\ ${ }^{2}$ Aalto University, Department of Forest Products \\ Technology, Vuorimiehentie 1, Espoo, Finland \\ ${ }^{3}$ VTT Technical Research Centre of Finland, Tietotie 2, \\ Espoo, Finland \\ * Corresponding author. \\ Bern University of Applied Sciences, Architecture, Wood and \\ Civil Engineering, Solothurnstrasse 102 CH-2500 Biel, \\ Switzerland \\ E-mail: christelle.ganne-chedeville@bfh.ch
}

\begin{abstract}
Spruce samples, naturally aged for 200, 400 and 500 years, artificially aged by a hydrothermal treatment (at 180,160 or $130^{\circ} \mathrm{C}$, relative air humidities of $14 \%, 40 \%$, or $60 \%$ and for treatment times between 1 to $50 \mathrm{~h}$ ), as well as reference samples, were analysed by Fourier transform infrared spectroscopy (FTIR) attenuated total reflection (FTIR-ATR) and ultraviolet resonance Raman (UVRR) spectroscopy. Natural ageing mostly affected the hemicelluloses and lignin, as observed from the FTIR-ATR and UVRR spectra, respectively. The UVRR spectra of the same samples after acetone extraction indicated that lignin was partially degraded and quinone structures were possibly formed. Artificial ageing at $160^{\circ} \mathrm{C}$ showed a significant change in the lignin structure, a well-known effect in the thermal treatment of wood, whereas treatment at $130^{\circ} \mathrm{C}$ did not alter the wood structure to any significant extent. Principal component analysis of the UVRR spectra confirmed that the spectra of artificially aged wood up to $160^{\circ} \mathrm{C}$ are dissimilar to naturally aged wood and which are also dissimilar to unaged wood.
\end{abstract}

Keywords: FTIR; heat-treated wood; PCA; UV resonance Raman spectroscopy (UVRRS); wood ageing.

\section{Introduction}

The slow deterioration of objects of cultural heritage is often called ageing; however, with appropriate storage and protection, ageing can be slowed down. Understanding how the mechanical and chemical properties of a material degrade over time can contribute to the knowledge of the most appropriate protection conditions. Ageing indoors must be differ- entiated from weathering outdoors, but even the former is a complex process, including physical and chemical changes on the surface, which is exposed to photo-modification and intensive oxidation, and in the bulk wood, i.e., below the surface. The interrelating factors triggering and influencing ageing are: the long-term exposure to fluctuating relative humidity; changes in ambient temperature; oxygen penetration into the bulk material; mechanical loading; and, in the worst case, fungi and bacteria. Deceleration and prevention of wood ageing is a topic of great interest to historians and conservationists.

Ageing and thermal treatment have similar effects (colour change, decrease of physical properties) as highlighted in a recent paper by Matsuo et al. (2011). Matsuo et al. compared the colour change of wood in historical buildings and heattreated wood and found that the colour change $\left(\Delta E^{*}{ }_{a b}\right)$ after 921 years at ambient temperature was almost equivalent to that of heating, which can be considered as artificial ageing, approximately for $6.7 \mathrm{~h}$ at $180^{\circ} \mathrm{C}$. Thus, the vast recent literature about thermal treating of wood gives a good opportunity to also gain insight into the slow processes of ageing (González-Peña and Hale 2009a,b; Bryne and Wålinder 2010; Bryne et al. 2010; Tuong and Li 2011). The relationship between chemical changes and mechanical properties of thermally treated wood is summarised by Windeisen et al. (2009). Also in the present study, artificial ageing by means of hydrothermal treatment was the preferred method.

Fourier transform infrared spectroscopy (FTIR) spectroscopy is an analytical technique well suited for studying the changes that take place in wood during ageing or weathering (Borgin et al. 1975; Fengel 1991; Horn et al. 1994; Müller et al. 2003; Pandey and Pitman 2003; Popescu et al. 2005; Uçar et al. 2005; Dobrica et al. 2008). It is recognised that a decrease in polyose content occurs during natural ageing as a result of a slow hydrolysis initiated by acetic acid which originates from cleaved $O$-acetyl groups of hemicelluloses. Similar observations were seen on thermal treated wood with infrared (IR) spectroscopy techniques (Pandey and Pitman 2003; Windeisen et al. 2003; Nuopponen et al. 2004; Tjeerdsma and Militz 2005; Windeisen and Wegener 2008). Thermal treatment also leads to the removal of extractives. During ageing, extractives move by evaporation, transportation by water movement, and diffusion towards the surface, and they are partly oxidised (Lavoie and Stevanovic 2006). The crystalline structure of cellulose in 300-400-year-old wood does not differ from fresh, unaged, wood. However, the degree of condensation of lignin and the number of polyconjugated systems increases as a result of oxidation and the amount of acid soluble lignin decreases (Borgin et al. 1975). In thermal treatment, a decrease in the amorphous polysaccharide content is observed, as well as condensation and 
demethoxylation of lignin (Tjeerdsma et al. 1998; Nuopponen et al. 2004).

The usefulness of FTIR combined to ultraviolet resonance Raman spectroscopy (UVRRS) was demonstrated by Nuopponen et al. $(2004,2005,2006)$. UVRRS is based on the sensitive interaction of lignin with UV light (Halttunen et al. 2001; Saariaho et al. 2003; Mononen et al. 2005; Nuopponen et al. 2006; Pandey and Vuorinen 2008), whereas the UV absorption by the hemicelluloses and cellulose is negligible.

Today, methods of chemometrics are an integral part of the utilization of modern hyphenated techniques. They make visible, even small changes, not otherwise visible at the first glance (Nuopponen et al. 2004, 2005; Martin et al. 2005). Chemometrics are frequently combined with FTIR and UVRRS; one speaks of multivariate data analysis with the approach partial least quares (PLS) or principal component analysis (PCA). PCA is suited for grouping of spectra, as well as for defining bands responsible for their similarities and dissimilarities (Ferraz et al. 2000; Saariaho et al. 2005; Esbensen 2009).

The aim of this study was to compare, both visually and with PCA, FTIR and UVRR spectra from un-aged wood, naturally aged wood and wood artificially aged by means of hydrothermal treatment. Qualitative and semi-quantitative analyses were performed. This approach should help draw conclusions as to the suitability of the different artificial ageing processes to reproduce the chemical changes occurring during natural ageing.

\section{Materials and methods}

\section{Wood samples}

Heartwood samples of spruce (Picea abies) wood were the focus of the study, namely: naturally aged old wood (OldW), wood artificially aged by hydrothermal treatment $(\mathrm{HtW})$ and recent (reference) wood (RefW). The 400 -year-old sample $(400 \mathrm{yW})$ was taken from a floorboard showing some radial cracks and visible insect attack, but no visible fungal attack. The 200- and 500-year-old samples $(200 \mathrm{yW}$ and $500 \mathrm{yW})$ were taken from beams used as structural elements in roofs. The age of the OldW samples was determined by dendrochronology. The parameters of artificial ageing of $\mathrm{HtW}$ samples are summarised in Table 1 . The samples were stabilised to their equilibrium moisture contents (EMC) at $20^{\circ} \mathrm{C}$ and $50 \%$ relative humidity (RH).

All specimens were taken not less than $7 \mathrm{~mm}$ away from the wood surface to avoid any influence of photo degradation or surface weathering. The specimens for FTIR spectroscopy were cut with a

Table 1 Description of the artificial ageing processes by hydrotreatment $(\mathrm{HtW})$ performed at 1 bar.

\begin{tabular}{lcccc}
\hline Series no. & Temp. $\left({ }^{\circ} \mathrm{C}\right)$ & $\mathrm{RH}(\%)$ & Time $(\mathrm{h})$ & $\begin{array}{l}\text { Abbreviation } \\
\mathrm{HtW}_{\text {Temp/RH/Time }}\end{array}$ \\
\hline 1 & 180 & 60 & 30 & $\mathrm{HtW}_{180 / 60 / 30}$ \\
& 160 & 14 & 50 & $\mathrm{HtW}_{160 / 14 / 50}$ \\
2 & 160 & 60 & 30 & $\mathrm{HtW}_{160 / 60 / 30}$ \\
& 130 & 40 & 1 & $\mathrm{HtW}_{130 / 40 / 1}$ \\
& 130 & 40 & 2 & $\mathrm{HtW}_{130 / 40 / 2}$ \\
& 130 & 40 & 10 & $\mathrm{HtW}_{130 / 40 / 10}$ \\
\hline
\end{tabular}

blade in the radial direction to obtain thin samples with dimensions of $0.05-0.1 \times 5 \times 20 \mathrm{~mm}^{3}(\mathrm{t} \times 1 \times \mathrm{r})$. Five pieces were prepared for each sample type. For the UVRRS measurements, eight wood specimens with dimensions of $0.7 \times 5 \times 25 \mathrm{~mm}^{3}(\mathrm{t} \times 1 \times \mathrm{r})$ were prepared from each sample type. They were cut with a chisel following the radial direction and the freshly cut surfaces were reserved for the measurement.

\section{Extractions}

Samples were extracted for $6 \mathrm{~h}$ with acetone in a Soxhlet apparatus. After evaporation of the acetone, the extracted specimens were dried at room temperature before further analyses.

\section{FTIR measurements}

Instrument: Spectrum 100 (Perkin Elmer, Waltham, MA, USA) spectrometer equipped with an attenuated total reflection (ATR) unit. Scanning range: 4000 and $650 \mathrm{~cm}^{-1} ; 32$ scans; resolution $4 \mathrm{~cm}^{-1}$. Baseline correction on four points (3960, 1784, 1545 and $782 \mathrm{~cm}^{-1}$ ); normalization to the highest absorption band between 1550 and $1500 \mathrm{~cm}^{-1}$. The spectral range $1800-600 \mathrm{~cm}^{-1}$ was evaluated. Each specimen was measured at five different positions on the freshly cut radial face.

\section{UVRR spectroscopy}

The specimens were attached to a microscope slide with doublesided tape with the freshly cut radial face on top and gently pressed with another slide to ensure good adhesion. Instrument: Renishaw 1000 UV Raman Spectrometer (Renishaw, Goucestershire, UK) equipped with a Leica DMLM microscope (Leica Microsystems, Wetzlar, Germany). Light source: Innova $90^{\circ} \mathrm{C}$ FreDTM frequencydouble $\mathrm{Ar}+$ ion laser (Coherent Inc., Santa Clara, CA, USA) tuned to an excitation wavelength of $244 \mathrm{~nm}$. Focus on the specimen was initially achieved with white light and a $40 \times$ objective lens. Then, the focus was adjusted to $30 \mu \mathrm{m}$ deeper, so as to get the UV laser beam to focus on the specimen surface. The laser power was kept at $1 \mathrm{~mW}$ and the specimens were moved slowly along a line perpendicular to the annual rings with a motorised sample stage. The acquisition time was $30 \mathrm{~s}$ (line distance $6 \mathrm{~mm}$ ), consisting of $2 \mathrm{CCD}$ readouts of $15 \mathrm{~s}$. The spectral data were analyzed by GRAMS/32 software (Thermo Galactic, Woburn, MA, USA). The spectra were normalised on the most intense band at $1602 \mathrm{~cm}^{-1}$ for easier comparison.

\section{PCA analysis of UVRR spectra}

PCA of normalised UVRR spectra was carried out by the Unscrambler X (CAMO Software AS., Oslo, Norway) software. Algorithm: NIPALS with systematic cross-validation and ascertainment test. A correlation optimised warping (COW) was performed to reduce the differences between the explained variance calibration and validation curves. Loadings and score were then plotted.

\section{Results and discussion}

\section{Qualitative analysis of FTIR ATR spectra}

Five FTIR-ATR spectra were collected from the recent reference sample (RefW) to check the spectral variation within the sample (Figure 1). Intensity differences were observed but, of course, no shifts of the principal bands were seen 


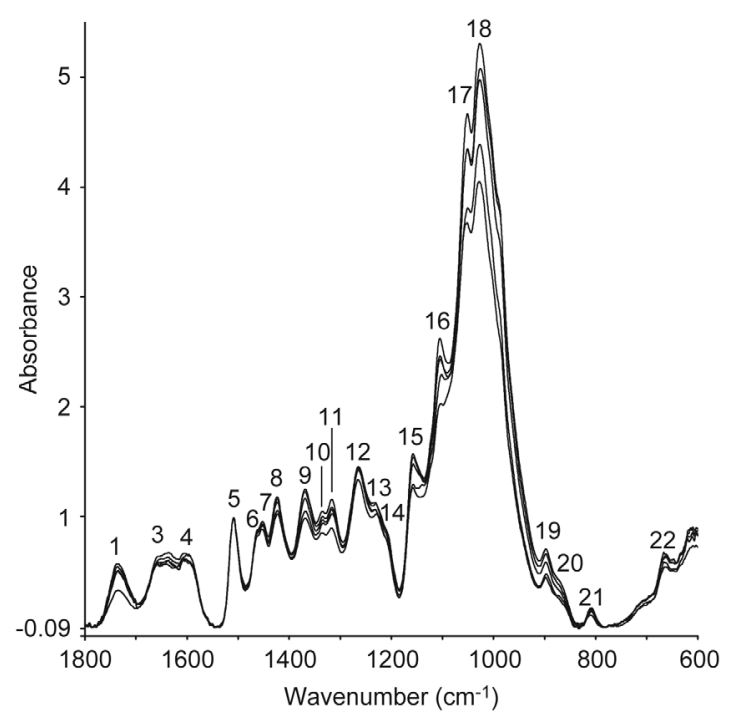

Figure 1 Five FTIR ATR spectra of the reference sample RefW in the fingerprint region. Numbers correspond to band assignment as described in Table 2.

(Figure 1). The differences in the band intensities are partly as a result of the heterogeneity of the measured material and differences in the surface quality, which also influence the quantification. To reduce errors from artefacts, the most representative spectra were selected from among the five spectra collected from each sample. The assignment of the 22 characteristic bands between $1800 \mathrm{~cm}^{-1}$ and $600 \mathrm{~cm}^{-1}$ are listed in Table 2 based on the literature (Faix 1992; Pandey and
Pitman 2003; Müller et al. 2008). A low frequency band at $664 \mathrm{~cm}^{-1}$ could not be assigned but it was considered in further analysis.

Figure 2 shows the characteristic FTIR ATR spectra of five different wood samples. The main changes in the spectra as a result of natural ageing (differences between the spectra of RefW and $400 \mathrm{yW}$ ) were observed in the range 1800-1500 $\mathrm{cm}^{-1}$ concerning the bands $1\left(1735 \mathrm{~cm}^{-1}\right), 3$ $\left(1641 \mathrm{~cm}^{-1}\right)$ and $4\left(1617 \mathrm{~cm}^{-1}\right)$. Natural ageing resulted in a decreasing intensity of bands 1 and 3 , whereas band 4 increased. These spectral changes were interpreted as modification of hemicelluloses. The $400 \mathrm{yW}$ sample is the only one in which the intensity of band $5\left(1508 \mathrm{~cm}^{-1}\right)$ was lower than that of band $4\left(1617 \mathrm{~cm}^{-1}\right)$. Bands 4 and 5 are attributable to the aromatic skeletal vibration of lignin. The artificially aged (HtW) samples did not show remarkable changes in this regard. A similar effect in the intensity of bands $4\left(1617 \mathrm{~cm}^{-1}\right)$ and $5\left(1508 \mathrm{~cm}^{-1}\right)$ was also observed after UV treatment of wood (Müller et al. 2003; Pandey and Vuorinen 2008) and was interpreted as lignin decay combined with the formation of new carbonyl groups evidencing photo-induced oxidation of the wood surface.

Artificial ageing by hydrotreatments $\mathrm{HtW}_{180 / 60 / 30}, \mathrm{HtW}_{160 /}$ ${ }_{14 / 50}$ and $\mathrm{HtW}_{160 / 60 / 30}$ (the indices are for temperature/RH/ time, respectively) also modified the band intensities in the 1800-1500 $\mathrm{cm}^{-1}$ range. A significant decrease in band 1 $\left(1735 \mathrm{~cm}^{-1}\right)$ and simultaneous increase in band $2\left(1700 \mathrm{~cm}^{-1}\right)$ was visible. Accordingly, esterified carbonyl structures in xylan decreased and free acid groups increased. The small shift of band $5\left(1508 \mathrm{~cm}^{-1}\right)$ to a lower wavenumber has been

Table 2 FTIR band assignment in the $1800-600 \mathrm{~cm}^{-1}$ region for different wood species (Faix 1992; Pandey and Pitman 2003; Müller et al. 2008).

\begin{tabular}{lccl}
\hline Band & Observed $\left(\mathrm{cm}^{-1}\right)$ & Lit. $\left(\mathrm{cm}^{-1}\right)$ & Compound or chemical group \\
\hline 1 & 1735 & 1732 & $\begin{array}{l}\text { C=O Stretch in xylan (hemicelluloses) } \\
\text { Shift of 1735 after Py, wood welding, and TM* }\end{array}$ \\
2 & 1700 & & $\begin{array}{l}\text { Absorbed O-H and conj. C-O; in Py: loss of water } \\
3\end{array}$ \\
1641 & 1649 & Arom. skeletal vibr. in L \\
4 & 1617 & 1593 & Arom. skeletal vibr. in L \\
5 & 1508 & 1505 & C-H def. in L and CH \\
6 & 1463 & 1460 & C-H def. in L and CHe \\
7 & 1452 & & Arom. skeletal vibr. in L with C-H def. \\
8 & 1423 & 1424 & C-H def. in cellulose and hemicell. \\
9 & 1368 & 1367 & S ring and G ring condensed \\
10 & 1335 & 1328 & C-H vibration in cellulose \\
11 & 1317 & 1318 & C-O stretch lignin ring in G units \\
12 & 1265 & 1267 & C-O stretch in G units \\
13 & 1231 & 1235 & Higher condensate structure in TM wood \\
14 & 1204 & $1245-1220$ & C-O-C vibration in cellulose and hemicell. \\
15 & 1157 & 1157 & Arom. skeletal vibr. and C-O stretch \\
16 & 1104 & 1122 & C-O vibr. in cellulose and hemicell. \\
17 & 1051 & & C-O vibr. in cellulose and hemicell. \\
18 & 1027 & 1031 & C-H def. in cellulose \\
19 & 897 & 897 & C-H out-of-plane arom. in L \\
20 & 877 & 859 & C-H out-of-plane arom. in L \\
21 & 808 & 818 & Unknown \\
22 & 664 & & \\
\hline
\end{tabular}

G, guaiacyl; S, syringyl; *TM, thermal modification, Windeisen and Wegener (2008); L, lignin. CH, carbohydrates. Py, pyrolysis. 


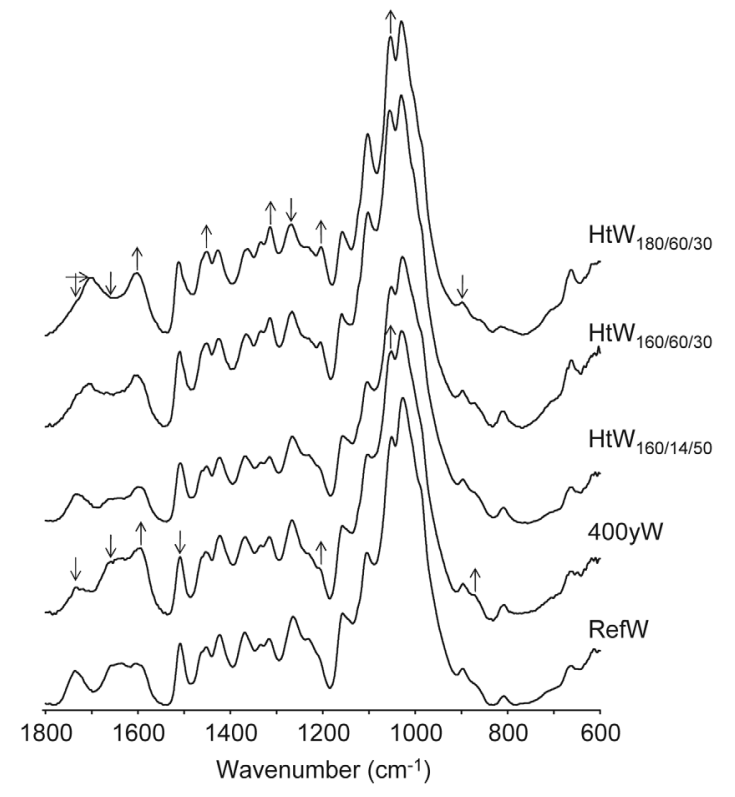

Figure 2 Qualitative analysis of the FTIR-ATR spectra of un-aged samples (RefW), 400-year-old sample (400yW) and hydrothermally treated samples of series $1\left(\mathrm{HtW}_{180 / 60 / 30}, \mathrm{HtW}_{160 / 14 / 50}, \mathrm{HtW}_{\text {160/60/30 }}\right)$. The arrows show the relative changes of intensity or the position of the several absorption bands.

attributed to the splitting of the aliphatic chains of lignin (Faix 1992; Uçar et al. 2005). An increase in the intensity of band $11\left(1317 \mathrm{~cm}^{-1}\right)$ as well as the shift of band 14 $\left(1204 \mathrm{~cm}^{-1}\right)$ has been attributed to the formation of condensed structures (Faix 1992). Artificial ageing by hydro-

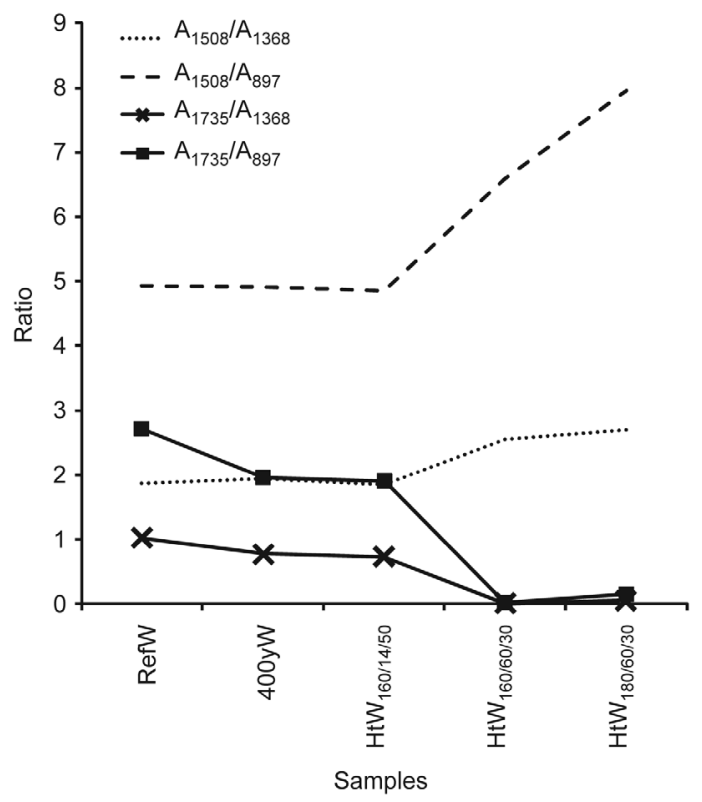

Figure 3 Corrected intensity ratio of the absorption bands which are characteristic for carbonyl, carbohydrate and lignin for unaged samples (RefW), 400-year-old samples (400yW) and hydrothermally treated samples of series $1\left(\mathrm{HtW}_{180 / 60 / 30}, \mathrm{HtW}_{160 / 14 / 50}\right.$, $\left.\mathrm{HtW}_{160 / 60 / 30}\right)$. treatment leads to the same types of chemical changes that were observed following the thermal treatment of wood. The mildest treatment in the case of $\mathrm{HtW}_{160 / 14 / 50}$ (i.e., treatment at $160^{\circ} \mathrm{C}, 14 \% \mathrm{RH}$ for $50 \mathrm{~h}$ ) resulted in spectral changes most similar to that of natural ageing.

\section{Semi-quantitative analysis of FTIR ATR spectra}

Semi-quantitative analysis was performed on the five spectra described above concerning the ratios of the 22 typical band intensities listed in Table 3. The intensity of the peak (height from the baseline) was corrected by calculating the height of the peak from the base of the peak. Ratios between the corrected intensity of band $1\left(1735 \mathrm{~cm}^{-1}\right.$, acetyl groups in xylan and other non-conjugated carbonyls), band $5\left(1508 \mathrm{~cm}^{-1}\right.$, the aromatic skeletal vibration of lignin), band 9 and 19 (1368 and $897 \mathrm{~cm}^{-1}$, carbohydrates) were calculated (Figure 3). All aged samples had lower carbonyl/carbohydrate ratios $\left(\mathrm{A}_{1735} /\right.$ $\mathrm{A}_{1368}$ and $\left.\mathrm{A}_{1735} / \mathrm{A}_{897}\right)$ than the reference samples. The lignin/ carbohydrate ratios $\left(\mathrm{A}_{1508} / \mathrm{A}_{1368}\right.$ and $\left.\mathrm{A}_{1508} / \mathrm{A}_{897}\right)$ were significantly higher for hydrothermal treatments up to $160^{\circ} \mathrm{C}$. The higher intensity of the aromatic skeletal vibration was probably the result of carbohydrate decomposition or the splitting of aliphatic chains in lignin and/or condensation reactions increasing the aromatic band intensity (Faix 1992; Uçar et al. 2005; Windeisen and Wegener 2008). The ratio of $\mathrm{A}_{1508} / \mathrm{A}_{1368}$ was slightly higher for sample $400 \mathrm{yW}$, which may also be explained by the formation of a higher number

Table 3 Relevant FTIR ATR absorption bands average corrected intensity of the studied samples and the reference (RefW).

\begin{tabular}{|c|c|c|c|c|c|}
\hline \multirow{3}{*}{$\begin{array}{l}\text { Band } \\
\left(\mathrm{cm}^{-1}\right)\end{array}$} & \multicolumn{5}{|c|}{ Base-line corrected band intensities } \\
\hline & \multirow[b]{2}{*}{ RefW } & \multirow[b]{2}{*}{$400 \mathrm{yW}_{\text {old }}$} & \multicolumn{3}{|c|}{$\begin{array}{l}\text { Wood aged by hydrothermal } \\
\text { treatment }\left(\mathrm{HtW}_{\text {Temp/RH/Time }}\right)\end{array}$} \\
\hline & & & $160 / 14 / 50$ & $160 / 60 / 30$ & $180 / 60 / 30$ \\
\hline 1735 & 0.451 & 0.344 & 0.310 & 0.003 & 0.017 \\
\hline 1700 & 0.000 & 0.000 & 0.020 & 0.375 & 0.506 \\
\hline 1640 & 0.212 & 0.163 & 0.013 & 0.010 & 0.011 \\
\hline 1616 & 0.306 & 0.500 & 0.295 & 0.466 & 0.661 \\
\hline 1508 & 0.800 & 0.860 & 0.789 & 0.805 & 0.860 \\
\hline 1462 & 0.089 & 0.080 & 0.085 & 0.088 & 0.074 \\
\hline 1452 & 0.097 & 0.109 & 0.106 & 0.107 & 0.118 \\
\hline 1423 & 0.421 & 0.469 & 0.407 & 0.356 & 0.342 \\
\hline 1368 & 0.438 & 0.442 & 0.426 & 0.316 & 0.319 \\
\hline 1334 & 0.052 & 0.075 & 0.055 & 0.084 & 0.089 \\
\hline 1316 & 0.215 & 0.291 & 0.213 & 0.306 & 0.302 \\
\hline 1264 & 0.527 & 0.633 & 0.477 & 0.442 & 0.444 \\
\hline 1230 & 0.069 & 0.062 & 0.052 & 0.045 & 0.050 \\
\hline 1204 & 0.091 & 0.145 & 0.110 & 0.177 & 0.260 \\
\hline 1157 & 0.592 & 0.790 & 0.781 & 0.799 & 0.776 \\
\hline 1103 & 0.366 & 0.563 & 0.613 & 0.657 & 1.033 \\
\hline 1051 & 0.528 & 0.775 & 0.728 & 0.841 & 0.958 \\
\hline 1026 & 0.977 & 1.044 & 1.037 & 0.853 & 0.900 \\
\hline 897 & 0.166 & 0.175 & 0.163 & 0.122 & 0.108 \\
\hline 876 & 0.011 & 0.012 & 0.000 & 0.040 & 0.040 \\
\hline 808 & 0.155 & 0.283 & 0.176 & 0.158 & 0.112 \\
\hline 664 & 0.196 & 0.238 & 0.189 & 0.229 & 0.277 \\
\hline
\end{tabular}



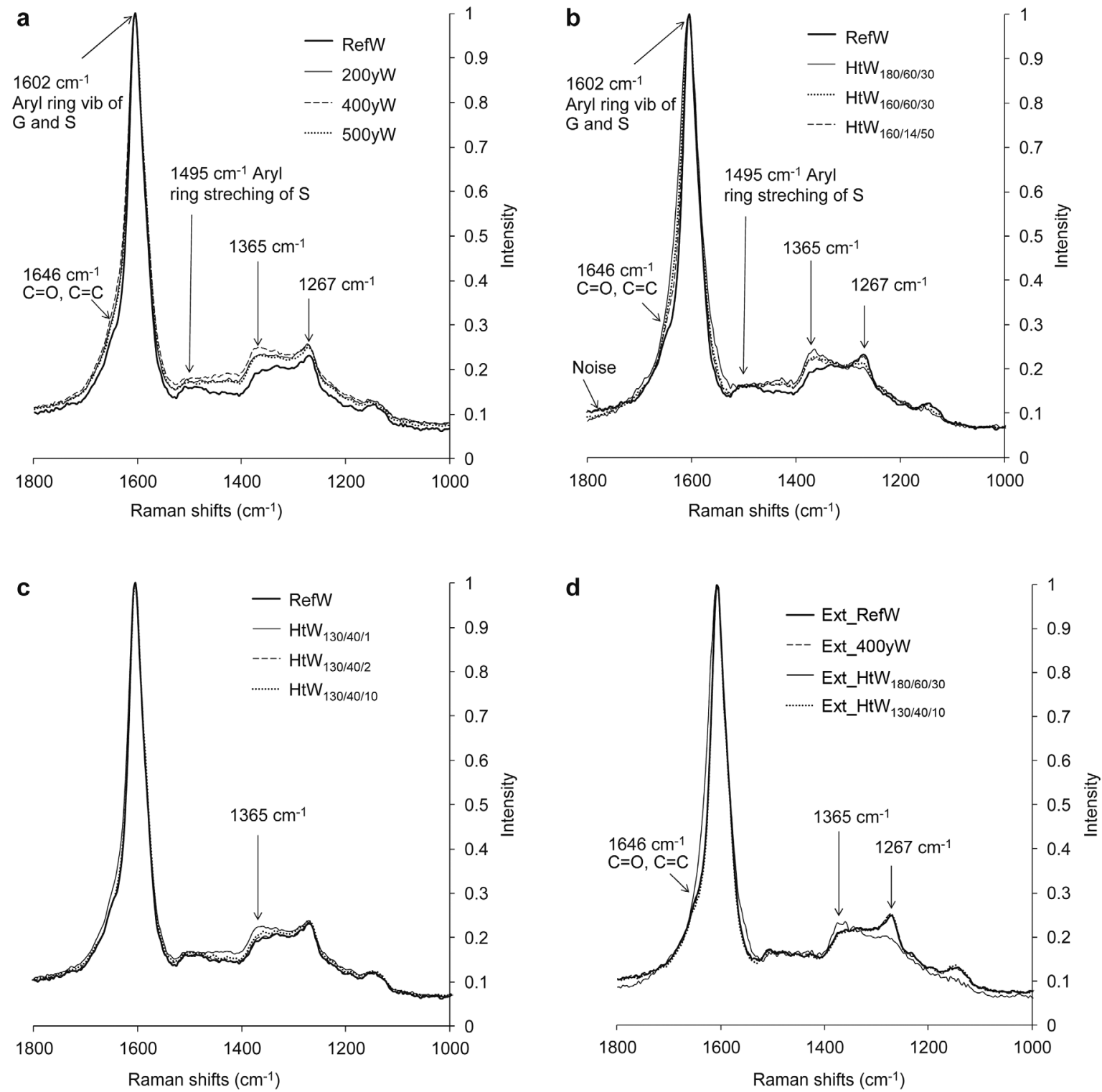

Figure 4 UVRR average spectra. (a) 200, 400, and 500-year-old spruce wood (200yW, 400yW, and 500yW) compared to recent sample (RefW). (b) Spruce wood hydrothermally treated samples of series 1 ( $\left.\mathrm{HtW}_{180 / 60 / 30}, \mathrm{HtW}_{160 / 14 / 50}, \mathrm{HtW}_{160 / 60 / 30}\right)$ up to $160^{\circ} \mathrm{C}$ compared to recent sample (RefW). (c) Spruce wood hydrothermally treated samples of series $2\left(\mathrm{HtW}_{130 / 40 / 1}, \mathrm{HtW}_{130 / 40 / 2}, \mathrm{HtW}_{130 / 40 / 10}\right)$ at $130^{\circ} \mathrm{C}$ compared with unaged sample (RefW). (d) Acetone-extracted naturally aged (ext_400yW), hydrothermally treated (ext_HtW $180 / 60 / 30$ and ext_HtW $130 /$ 40/10) spruce wood samples compared to acetone-extracted recent sample (ext_RefW). The main absorption bands showing differences are indicated with arrows.

Table 4 UVRR band assignment in the $1700-1100 \mathrm{~cm}^{-1}$ region for different wood species (Agarwal 1999; Saariho et al. 2003; Pandey and Vuorinen 2008).

\begin{tabular}{lccl}
\hline Band & Found $\left(\mathrm{cm}^{-1}\right)$ & Lit. $\left(\mathrm{cm}^{-1}\right)$ & \multicolumn{1}{c}{ Compound or chemical group } \\
\hline 1 & 1646 & 1645 & Unsaturated structures of resin acids \\
2 & 1602 & 1605 & Sym. aryl ring stretch. of G and S \\
3 & 1495 & 1502 & Asym. aryl ring stretch. vibr. of S \\
4 & 1365 & 1368 & Phenolic and/or cond. structure of L \\
5 & 1267 & 1270 & Arom. ether in G \\
6 & 1150 & 1152 & Delta phenol mode of G \\
\hline
\end{tabular}

G, guaiacyl; S, syringyl. 
of condensed structures in the lignin of naturally aged (old) samples.

\section{UVRRS of non-extracted samples}

For each sample, an average spectrum was calculated from eight UVRRS. The band assignment based on the literature in presented in Table 4. In all cases, the absorption band at $1605 \mathrm{~cm}^{-1}$ was the most prominent (aromatic ring vibrations).

The intensities of the bands within $1300-1500 \mathrm{~cm}^{-1}$, attributed to the guaiacyl groups of the lignin, were higher in OldW than in RefW (Figure 4a). The small increase of the relative intensities in this region compared to the reference peak at $1602 \mathrm{~cm}^{-1}$ may be as a result of a slight increase in unsaturated structures resulting from lignin degradation. In the case of UV irradiated wood, the intensity changes were similar, but more intense (Pandey and Vuorinen 2008). The $400 \mathrm{yW}$ sample showed a band at $1365 \mathrm{~cm}^{-1}$ with slightly higher intensity in comparison with the spectra of $500 \mathrm{yW}$ and 200yW. Consequently, differences observed between the OldW spectra are not related to the age of the sample. Other ageing factors (such as changes in moisture content or mechanical loading), independent of time, may be responsible for the small differences observed. As the $400 \mathrm{yW}$ specimen was taken from a floorboard, it could well have been more mechanically stressed than the $200 \mathrm{yW}$ or $500 \mathrm{yW}$ samples, which were taken from roof beams. Repeated adsorption and desorption resulting from washing and drying of the floor might be also be a reason for such differences (Froidevaux et al. 2011).

Changes in the spectra of $\mathrm{HtW}$ samples treated up to $160^{\circ} \mathrm{C}$ (Figure $4 \mathrm{~b}$ ) were similar to the changes observed in thermally treated wood, but were less pronounced (Nuopponen et al. 2005). There was a significant increase in the absorption band at $1365 \mathrm{~cm}^{-1}$ and a significant decrease in the band at $1262 \mathrm{~cm}^{-1}$ for treatment types $\mathrm{HtW}_{180 / 60 / 30}$ and $\mathrm{HtW}_{160 / 60 / 30}$. This indicates that guaiacyl structures were modified at high temperatures. Moreover, the band at $1646 \mathrm{~cm}^{-1}$ was decreased and the bands at $1602 \mathrm{~cm}^{-1}$ and in the region $1700-1550 \mathrm{~cm}^{-1}$ were broadening for the samples $\mathrm{HtW}_{180 / 60 / 30}$ and $\mathrm{HtW}_{160 / 60 / 30}$. Pandey and Vuorinen (2008) observed the same intensity changes in UV irradiated spruce and explained it by the formation of $o$ - and $p$-quinone type structures. The same was true for thermomechanical pulps (Agarwal 1998; Jääskeläinen et al. 2006). Treatment type $\mathrm{HtW}_{160 / 14 / 50}$ exhibited the same characteristics but were less pronounced than the treatments $\mathrm{HtW}_{180 / 60 / 30}$ and $\mathrm{HtW}_{160 / 60 / 30}$.

The UVRR spectra of the HtW samples of series 2 at $130^{\circ} \mathrm{C}\left(\mathrm{HtW}_{130 / 40 / 1}, \mathrm{HtW}_{130 / 40 / 2}\right.$, and $\left.\mathrm{HtW}_{130 / 40 / 10}\right)$ were similar to RefW (Figure 4c). Only a slight increase in the band at $1365 \mathrm{~cm}^{-1}$ was visible. The lignin structures did not change following this treatment compared to RefW.

\section{UVRRS of acetone extracted samples}

Soxhlet extraction should help defining which lignin band is overlapping with acetone extractable substances. The UVRR spectra of the acetone extracted samples, RefW, 400yW, $\mathrm{HtW}_{180 / 60 / 30}$, and $\mathrm{HtW}_{130 / 40 / 10}$ are presented in Figure 4d.
With the exception of the $\mathrm{HtW}_{180 / 60 / 30}$ spectra, all spectra are nearly identical and the slight differences observed on nonextracted samples are not perceptible. Consequently, the slight UVRR spectral differences described above (between OldW, RefW, and HtW) were caused by acetone-extractable compounds. These are probably lignans or lignin degradation products (Rogers et al. 1967; Kawamura et al. 1998). Such compounds are also generated during the photo-discoloration of wood under UV-light. As the specimens were taken from layers not penetrated by UV-light, the amount of acetonextractables could increase as a result of a sub-surface degradation caused by longer wavelength light that still has sufficient energy to degrade wood (Hon et al. 1980; Kataoka et al. 2007).

\section{PCA of UVRR spectra}

The UVRR spectra of all non-extracted samples were evaluated by PCA. The first principal component (PC1) explained $49 \%$ and the second principal component (PC2) explained $33 \%$ of the differences between the spectra. Other successive PC explained no more than $5 \%$ of the dissimilarities and, consequently, the analysis was limited to PC1 and PC2. The plotted scores of PC1 vs. PC2 (Figure 5) shows the two largest variations in magnitude within the data and the spectra are separated on the plot. Spectra of the sample $\mathrm{HtW}_{180 / 60 / 30}$ and $\mathrm{HtW}_{160 / 60 / 30}$ form individual groups which were well separated from the other samples. They both had positive values of PC1 and PC2, which was not the case for other groups of compounds. The other groups were overlapping with each other, which means that they were more similar. The position of OldW $(\mathrm{PC} 1>0$ and $\mathrm{PC} 2<0)$ is opposite
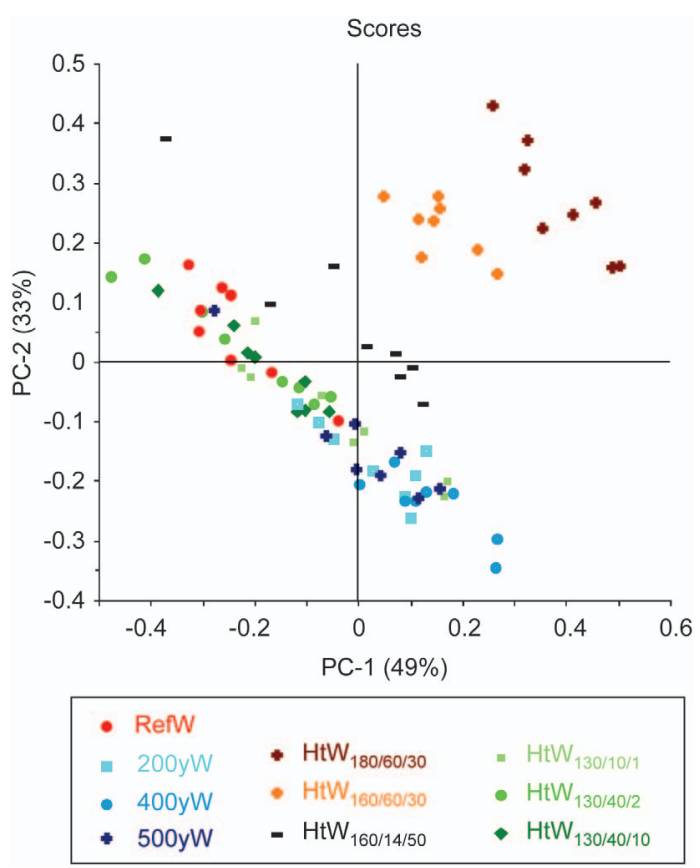

Figure 5 Principal component analysis from UVRR spectra collected for all sample sets. 

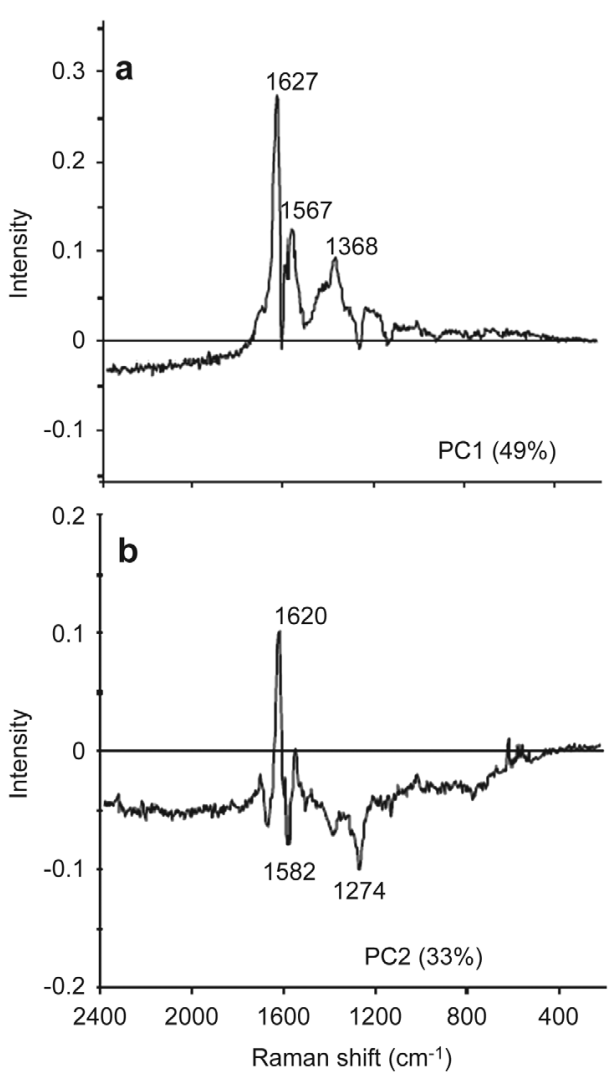

Figure 6 (a) Loading of the first principal component (PC1) of the UVRR spectra for all sets. (b) Loading of the second principal component (PC2) of the UVRR spectra for all sets.

to that of RefW (PC1 $<0$ and PC2 $>0$ ). Nevertheless, careful interpretation is needed, as the groups are partly overlapping.

The loadings plot of $\mathrm{PC} 1$ and $\mathrm{PC} 2$ provides information on the bands which are responsible for grouping of the samples. The loading for PC1 (Figure 6a) shows that bands at $1627 \mathrm{~cm}^{-1}, 1567 \mathrm{~cm}^{-1}$ (o- and $p$-quinone type structures) and $1368 \mathrm{~cm}^{-1}$ (phenolic and/or condensed structures of lignin) are mainly responsible for the grouping of sample types $\mathrm{HtW}_{180 / 60 / 30}$ and $\mathrm{HtW}_{160 / 60 / 30}$. The loading of PC2 (Figure 6b) reveals that the band at $1620 \mathrm{~cm}^{-1}$ (o- and $p$-quinone type structures) gives a positive loading and is also responsible for the grouping of samples in discussion. Grouping of the OldW samples $(\mathrm{PC} 2<0)$ seems to be caused by the bands at $1582 \mathrm{~cm}^{-1}$ (broadening of the absorption band at $1602 \mathrm{~cm}^{-1}$ ) and at $1274 \mathrm{~cm}^{-1}$ (aromatic ether units in guaiacyl structures).

\section{Conclusions}

Spectroscopic data of naturally aged wood samples are not changed to a great extent. According to FTIR spectra, hemicelluloses are deteriorated in naturally aged spruce samples. The UVRR spectra of naturally aged wood show that the small differences compared with a recent reference wood are caused by acetone-extractable compounds. These compounds could include degradation products of lignin or unsaturated wood extractives. No specific correlation could be found between the age from 200 to 500 years and spectral changes, confirming that time alone is not the only factor affecting the chemistry of wood during ageing. Additional factors, such as humidity, insects, fungi and the origin of the wood influence the changes. For artificial ageing by hydrotreatment up to $160^{\circ} \mathrm{C}$, the changes in lignin were significant, as is the case for thermally treated wood. Samples from hydrotreatment at $130^{\circ} \mathrm{C}$ do not differ from the reference sample. Probably, the analytical power of FTIR and UVRRS is limited, and thus additional methods, such as ${ }^{13} \mathrm{C}$ NMR or wet chemical analyses, are needed to gain more insight into ageing.

\section{Acknowledgments}

Financial support from the Swiss National Foundation Project nr K21K-122336/1, from the Bern University of Applied Sciences and from the Regional Council of Lorraine in France is gratefully acknowledged. Dr C. Ganne-Chédeville expresses her sincere thanks to Professor Tapani Vuorinen, Head of the Department of Forest Products Technology and Lauri Rautkari for support during her visit to Aalto University. Rita Hatakka from the Department of Forest Products Technology at Aalto University is thanked for advice in UVRR spectroscopy. Dr A-S Jääskeläinen acknowledges the Academy of Finland for financial support.

\section{References}

Agarwal, U. (1998) Assignment of the photoyellowing-related $1675 \mathrm{~cm}^{-1}$ Raman/IR band to $p$-quinones and its implications to the mechanism of color reversion in mechanical pulp. J. Wood Chem. Technol. 18:381-402.

Borgin, K., Faix, O., Schweers, W. (1975) The effect of aging in lignins of wood. Wood Sci. Technol. 9:207-211.

Bryne, L.E., Wålinder, M.E.P. (2010) Ageing of modified wood. Part 1: Wetting properties of acetylated, furfurylated, and thermally modified wood. Holzforschung 64:295-304.

Bryne, L.E., Lausmaa, J., Ernstsson, M., Englund, F., Wålinder, M.E.P. (2010) Ageing of modified wood. Part 2: Determination of surface composition of acetylated, furfurylated, and thermally modified wood by XPS and ToF-SIMS. Holzforschung 64:305313.

Dobrica, I., Bugheanu, P., Stanculescu, I., Ponta, C. (2008) FTIR spectral data of wood used in Romanian traditional village constructions. Analele Universitatii din Bucuresti XVII:33-37.

Esbensen, K.H. (2009) Multivariate Data Analysis-In Practice, $5^{\text {th }}$ Edition. Camo Software AS., Oslo, Norway.

Faix, O. (1992) Fourier transform infrared spectroscopy. In: Methods in Lignin Chemistry. Eds Lin, S.Y., Dence, C.W. Springer-Verlag, Berlin, Heidelberg, New York, pp. 83-109.

Fengel, D. (1991) Ageing and fossilization of wood and its components. Wood Sci. Technol. 25:153-177.

Ferraz, A., Baeza, J., Rodriguez, J., Freer, J. (2000) Estimating the chemical composition of biodegraded pine and eucalyptus wood by DRIFT spectroscopy and multivariate analysis. Bioresour. Technol. 74:201-212.

Froidevaux, J., Volkmer, T., Ganne-Chédeville, C., Gril, J., Navi, P. (2011) Viscoelasticity behavior of aged and non-aged spruce wood in radial direction. Wood Mater. Sci. Eng. (in press). 
González-Peña, M.M., Hale, M.D.C. (2009a) Colour in thermally modified wood of beech, Norway spruce and Scots pine. Part 1: Colour evolution and colour changes. Holzforschung 63:385393.

González-Peña, M.M., Hale, M.D.C. (2009b) Colour in thermally modified wood of beech, Norway spruce and Scots pine. Part 2: Property predictions from colour changes. Holzforschung 63:394-401.

Halttunen, M., Vyörykkä, J., Hortling, B., Tamminen, T., Batchelder, D., Zimmermann, A., Vuorinen, T. (2001) Study of residual lignin in pulp by UV resonance Raman spectroscopy. Holzforschung 55:631-638.

Hon, D.N.-S., Ifju, G., Feist, W.C. (1980) Characteristics of free radicals in wood. Wood Fiber Sci. 12:121-130.

Horn, B.A., Qiu, J., Owen, N.L., Feist, W.C. (1994) FT-IR studies of weathering effects in Western Redcedar and Southern Pine. Appl. Spectrosc. 48:662-668.

Jääskeläinen, A.-S., Saariaho, A.-M., Vyörykkä, J., Vuorinen, T., Mtousek, P., Parker, A.W. (2006) Application of UV-Vis and resonance Raman spectroscopy to study bleaching and photoyellowing of thermomechanical pulps. Holzforschung 60:231-238.

Kataoka, Y., Kiguchi, M., Williams, R.S., Evans, P.D. (2007) Violet light causes photodegradation of wood beyond the zone affected by ultraviolet radiation. Holzforschung 61:23-27.

Kawamura, F., Miyachi, M., Kawai, S., Ohashi, H. (1998) Photodiscoloration of western hemlock (Tsuga Heterophylla) sapwood III*. Early stage of photodiscoloration reaction with lignans. J. Wood Sci. 44:47-55.

Lavoie, J.-M., Stevanovic, T. (2006) Yield and composition of lipophylic extracts of yellow birch (Betula alleghaniensis Britton) as a function of wood age and aging under industrial conditions. Holzforschung 60:184-189.

Martin, Z.M., Labbé, N., Rials, T.G., Wullschleger, S.D. (2005) Analysis of preservative-treated wood by multivariate analysis of laser-induced breakdown spectroscopy sprectra. Spectrochim. Acta, Part B 60:1179-1185.

Matsuo, M., Yokoyama, M., Umemura, K., Sugiyama, J., Kawai, S., Gril, J., Kubodera, S., Mitsutani, T., Ozaki, H., Sakamoto, M., Imamura, M. (2011) Aging of wood: analysis of color changes during natural aging and heat treatment. Holzforschung 65:361-368.

Mononen, K., Jääskeläinen, A.-S., Alvila, L., Pakkanen, T.T., Vuorinen, T. (2005) Chemical changes in silver birch (Betula pendula Roth) wood caused by hydrogen peroxide bleaching and monitored by color measurement (CIELab) and UV-Vis, FTIR and UVRR spectroscopy. Holzforschung 59:381-388.

Müller, G.S. FTIR-ATR spectroscopic and FTIR-FPA microscopic investigations on panel board production processes using Grand fir (Abies grandis (Douglas ex D. Don) Lindl. and European beech (Fagus sylvatica L.). PhD thesis of the University of Göttingen, Göttingen, Germany, 2008.

Müller, U., Rätzsch, M., Schwanninger, M., Steiner, M., Zöbl, H. (2003) Yellowing and IR-changes of spruce wood as result of UV-irradiation. J. Photochem. Photobiol. B. Biology 69:97-105.

Nuopponen, M., Wikberg, A., Vuorinen, T., Maunu, S.L., Jämsä, S., Viitaniemi, P. (2004) Heat-treated softwood exposed to weathering. J. Appl. Polym. Sci. 91:2128-2134.
Nuopponen, M., Vuorinen, T., Jämsä, S., Viitaniemi, P. (2005) Thermal modifications in softwood studied by FT-IR and UV resonance Raman spectroscopies. J. Wood Chem. Technol. 24: $13-26$.

Nuopponen, M., Wikberg, H.I., Birch, G.M., Jääskeläinen, A.-S., Maunu, S.L., Vuorinen, T., Stewart, D. (2006) Characterization of 25 tropical hardwoods with Fourier transform infrared, ultraviolet resonance Raman and ${ }^{13} \mathrm{C}-\mathrm{NMR}$ cross-polarization/magicangle spinning spectroscopy. J. Appl. Polym. Sci. 102:810-819.

Pandey, K.K., Pitman, A.J. (2003) FTIR studies of the changes in wood chemistry following decay by brown-rot and white-rot fungi. Int. Biodeterior. Biodegrad. 52:151-160.

Pandey, K.K., Vuorinen, T. (2008) UV resonance Raman spectroscopic study of photodegradation of hardwood and softwood lignins by UV laser. Holzforschung 62:183-188.

Popescu, C.-M., Sakata, Y., Popescu, M.-C., Osaka, A., Vasile, C. (2005) Degradation of lime wood painting supports. E-Preservation Science 2:19-29.

Rogers, I.H. A review of the wood and bark extractives of spruces. Department of Forestry and Rural Development, Otawa, Canada, 1967.

Saariaho, A.-M., Jääskeläinen, A.-S., Nuopponen, M., Vuorinen, T. (2003) Ultra violet resonance Raman spectroscopy in lignin analysis: determination of characteristic vibrations of $\mathrm{p}$ hydroxylphenyl, guaiacyl, and syringyl lignin structures. Appl. Spectrosc. 57:58-66.

Saariaho, A.-M., Argyropoulos, D.S., Jääskeläinen, A.-S., Vuorinen, T. (2005) Development of the partial least squares models for the interpretation of the UV resonance Raman spectra of lignin model compounds. Vib. Spectrosc. 37:111-121.

Tjeerdsma, B.F., Militz, H. (2005) Chemical changes in hydrothermal treated wood: FTIR analysis of combined hydrothermal and dry heat-treated wood. Holz Roh Werkst. 63:102-111.

Tjeerdsma, B.F., Boonstra, M., Pizzi, A., Tekely, P., Militz, H. (1998) Characterisation of thermally modified wood: molecular reasons for wood performance improvement. Holz Roh Werkst. 56:149-153.

Tuong, V.M., Li, J. (2011) Changes caused by heat treatment in chemical composition and some physical properties of acacia hybrid sapwood. Holzforschung 65:67-72.

Uçar, G., Meier, D., Faix, O., Wegener, G. (2005) Analytical pyrolysis and FTIR spectroscopy of fossil Sequoiadendron giganteum (Lindl.) wood and MWLs isolated hereof. Holz Roh Werkst. 63:57-63.

Windeisen, E., Wegener, G. (2008) Behaviour of lignin during thermal treatments of wood. Ind. Crops Prod. 27:157-162.

Windeisen, E., Strobel, C., Wegener, G. (2003) Chemische Charakterisierung von thermisch belastetem Holz: Bestimmung des Acetylgruppengehalts und FTIR-Spektroskopie. Holz Roh Werkst. 61:471-472.

Windeisen, E., Bächle, H., Zimmer, B., Wegener, G. (2009) Relations between chemical changes and mechanical properties of thermally treated wood $10^{\text {th }}$ EWLP, Stockholm, Sweden, August 25-28, 2008. Holzforschung 63:773-778.

Received January 17, 2011. Accepted August 8, 2011.

Previously published online September 9, 2011. 